\title{
Treatment of community-acquired lower respiratory tract infections in adults
}

\author{
Å. Örtqvist
}

Treatment of community-acquired lower respiratory tract infections in adults. A. Örtqvist. C ERS Journals Ltd 2002.

ABSTRACT: Community-acquired lower respiratory tract infection (LRTI) is a common cause of acute illness in adults. The spectrum of disease ranges from a mild mucosal colonisation or infection, acute bronchitis or acute exacerbation of chronic bronchitis/chronic obstructive pulmonary disease (AE-CB/COPD), to an overwhelming parenchymal infection with the patient presenting with severe community-acquired pneumonia (CAP).

Although the great majority of LRTIs are self-limiting viral infections, CAP is most often a bacterial disease with a substantial mortality. Thus, antibiotic treatment is rarely indicated for acute bronchitis and is only indicated for the more severe cases of AE-CB/COPD, but it is nearly always indicated for CAP, for which a delay in treatment may increase the risk of a fatal outcome. It may be difficult to differentiate between a viral and a bacterial LRTI, or between bronchitis/AE-CB/COPD and CAP. This may be one reason why antibiotics are prescribed to more than two-thirds of patients with LRTIs in Europe and the USA. Considering the worldwide development of antibiotic resistance, this is not an acceptable situation.

Since an empirical approach is nearly always necessary in the management of LRTI, greater emphasis must be placed on the decision of whether or not to prescribe an antibiotic at all. This decision should be based on an assessment of the severity of the disease, including underlying risk factors, and on markers for bacterial/parenchymal/ invasive LRTI. The choice of empirical therapy must be based on the same data together with epidemiological information. The choice of antibiotic must always cover Streptococcus pneumoniae, which remains the main pathogen of morbidity and mortality in CAP. In hospital, attempts should be made to obtain an aetiological diagnosis in order to be able to switch to a specific treatment or to evaluate a failure of empirical therapy.

Several guidelines for the management of community-acquired pneumonia have been published during the last 10 yrs. Some reports indicate that the implementation of such guidelines has resulted in lowered costs, length of stay in hospital and mortality. However, the results from these studies are not consistent and the evidence is still weak. Eur Respir J 2002; 20: Suppl. 36: 40s-53s.

\author{
Correspondence: Å. Örtqvist \\ Dept of Infectious Diseases \\ Karolinska Institutet \\ Karolinska Hospital \\ SE-171 76 Stockholm \\ Sweden \\ Fax: 46851771804 \\ E-mail: ake.ortqvist $@$ ks.se
}

Keywords: Bacterial infection bronchitis

lower respiratory tract infection pneumonia

viral infection

Received: January 252002

Accepted after revision: March 42002
There are great systematic differences in the prescription of antibiotics, both overall and for lower respiratory tract infections (LRTIs), between countries and between different healthcare providers in the same country [1-5]. During the 1990s, there was an enormous amount of research activity in the field of LRTIs, especially concerning community-acquired pneumonia (CAP). Several guidelines for the management of CAP have been published. The "first generation" of guidelines was mostly consensus-based [6-11], whereas those published in 2000/2001 are at least partly evidence-based [12-15]. However, there is still a lack of evidence in many areas of the LRTI field, and, in addition, interpretation of the available evidence is variable in some cases. Thus, the present article is a personal interpretation of the available data on when, and how, to use antimicrobial therapy in LRTI. This interpretation is most probably biased by the rather conservative antibiotic regimens and limited problems with antimicrobial resistance in Scandinavia.
Morbidity and mortality

Community-acquired LRTI is a very common cause of acute illness and probably the most common reason for lost working time in adults. The spectrum of disease ranges from a mild mucosal colonisation or infection, an acute bronchitis or acute exacerbation of chronic bronchitis/chronic obstructive pulmonary disease (AE-CB/COPD), to an overwhelming parenchymal infection with the patient presenting with a severe CAP. There is no gold standard for the diagnosis of pneumonia or acute bronchitis, something which must be taken into account when incidence rates differ between studies. In addition, there are limited data concerning the incidence of mild LRTI, since most estimates are based on contacts with healthcare. According to a recent review, the annual incidence of adult patients with LRTIs consulting healthcare providers, ranges $8-124$ per 1,000 population, depending on age, sex and type of diagnosis [16]. 
A sharp increase in the incidence of LRTI is seen in persons of $>70-75$ yrs of age, and males seem to be at greater risk of these diseases than females.

The majority of LRTIs are self-limiting viral infections. The overall mortality of this group of diseases is very low [17]. However, pneumonia, which probably accounts for $<5 \%$ of all LRTIs, is most often a bacterial disease with a substantial annual mortality; ranging from $0.2 \%$ for elderly persons in the community [18] to $14 \%$ for those hospitalised with CAP [19], and as high as $\geqslant 50 \%$ in subgroups of patients presenting with septic shock [20]. Thus, pneumonia should, in general, be treated with antibiotics. It is also important to start treatment promptly, since a delay of $>8 \mathrm{~h}$ in treatment is associated with increased mortality [21].

\section{Important factors on which to base antibiotic treatment of lower respiratory tract infection}

\section{Bronchitis or pneumonia?}

The clinical manifestations of acute bronchitis may be similar to those of CAP. A new infiltrate on chest radiography is most often considered the gold standard for the diagnosis of CAP. Unfortunately, there seems to be no single clinical finding, or combination of findings, that can reliably predict radiological pneumonia $[12,17]$. Acute cough and low-grade fever, in association with upper respiratory tract symptoms such as a sore throat and a runny nose, are most probably due to viral bronchitis. Conversely, features such as high fever $\left(>38^{\circ} \mathrm{C}\right)$ or chills, cough with purulent expectoration, pleural pain, tachypnoea and new focal signs on physical examination of the chest most probably indicate the presence of pneumonia. However, many patients consult their general practitioner with symptoms and signs between those two "extremes", and all too often an antibiotic will be prescribed for a viral LRTI. Bearing in mind that pneumonia causes only $\leqslant 5 \%$ of all LRTIs, it is unacceptable that antibiotics are prescribed to at least two-thirds of patients with LRTIs in both Europe and the USA $[22,23]$. It has been estimated that viral respiratory tract infections alone result in as much as one-fifth of all antibiotic prescriptions in adults [23]. Considering the risk of death in CAP, it is, of course, more important not to fail to prescribe an antibiotic to a pneumonia patient than it is to avoid giving out an unnecessary prescription to a patient with a viral bronchitis. However, the amount of antibiotics used is clearly related to the rate of antimicrobial resistance in the community [24], and overuse will result in not only increased direct costs for drugs but also decreased effectiveness of the drugs available for treatment of CAP. More frequent use of chest radiography to differentiate between bronchitis and CAP may, therefore, be cost-effective in the long run. Of laboratory tests, C-reactive protein (CRP) measurement is probably the one analysis that is both readily available, even in the general practitioner's office, and has a reasonable sensitivity and specificity for differentiating between parenchymal involvement and endobronchial disease. Although there is no clearcut division between these two entities, the majority of endobronchial infections will result in normal or very low CRP levels, whereas most cases of pneumonia result in a CRP level of $>50-100 \mathrm{mg} \cdot \mathrm{L}^{-1}[25-29]$. The present author's recommendations for differential diagnosis between acute bronchitis and CAP in an immunocompetent adult without chronic pulmonary disease are shown in figure 1 .

\section{How important are "atypical agents" ?}

All recent CAP guidelines advocate the routine use of antibiotics effective against "atypical pathogens" for inpatients [12-15], and only one recommends a $\beta$-lactam alone as an alternative first choice for outpatient treatment [14]. However, the question is how important it is always to cover for "atypical agents".

Streptococcus pneumoniae remains the most common pathogen of CAP among patients requiring admission to hospital, as well as the pathogen most often associated with bacteraemic disease, need for intensive care unit (ICU) treatment and death [12, 30]. Although Mycoplasma pneumoniae is the most common finding in aetiological investigations among outpatients, blood and sputum cultures have rarely been included in these studies and it is, therefore, likely that $S$. pneumoniae has been underdiagnosed [30]. This is supported by a population-based study from Finland, in which $M$. pneumoniae was a more frequent finding among outpatients than inpatients (14 versus 5\%, $\mathrm{p}=0.02$ ), but in which $S$. pneumoniae was the most common finding in both outpatients (44\%) and inpatients $(50 \%)$ [31]. M. pneumoniae has been recognised as a cause of LRTI for many years, is an endemic pathogen, or comes in epidemic cycles, and most often causes a relatively mild CAP in adolescents and young adults. Since the end of the 1970s, legionella has been known to cause pneumonia. As freshwater is the natural habitat of this pathogen, legionnaires' disease is endemic in some geographical areas, and sporadic outbreaks may occur by inhalation of aerosolised infected water generated from showers, cooling towers, whirlpools, etc. Legionella spp. is a relatively frequent cause of severe pneumonia, much more so than mycoplasma, and, although this pathogen may be uncommon in some areas, it is often the second most common finding in studies of the aetiology of CAP requiring ICU treatment [32]. During the 1990s, the use of sensitive new diagnostic techniques implicated Chlamydia pneumoniae as a common cause of CAP, accounting for $1-15 \%$ of cases outside epidemic situations and up to $40 \%$ during outbreaks [33]. There is no doubt that $C$. pneumoniae may cause CAP, and, in some instances, also severe infection [34]. However, the diagnosis of $C$. pneumoniae pneumonia is made serologically or by polymerase chain reaction techniques, and, since there are no validated criteria to define under what circumstances $C$. pneumoniae should be considered the cause of pneumonia, there is a clear risk of overdiagnosis of this pathogen. In addition, and similar to mycoplasma, chlamydia is relatively often detected in mixed infections with 


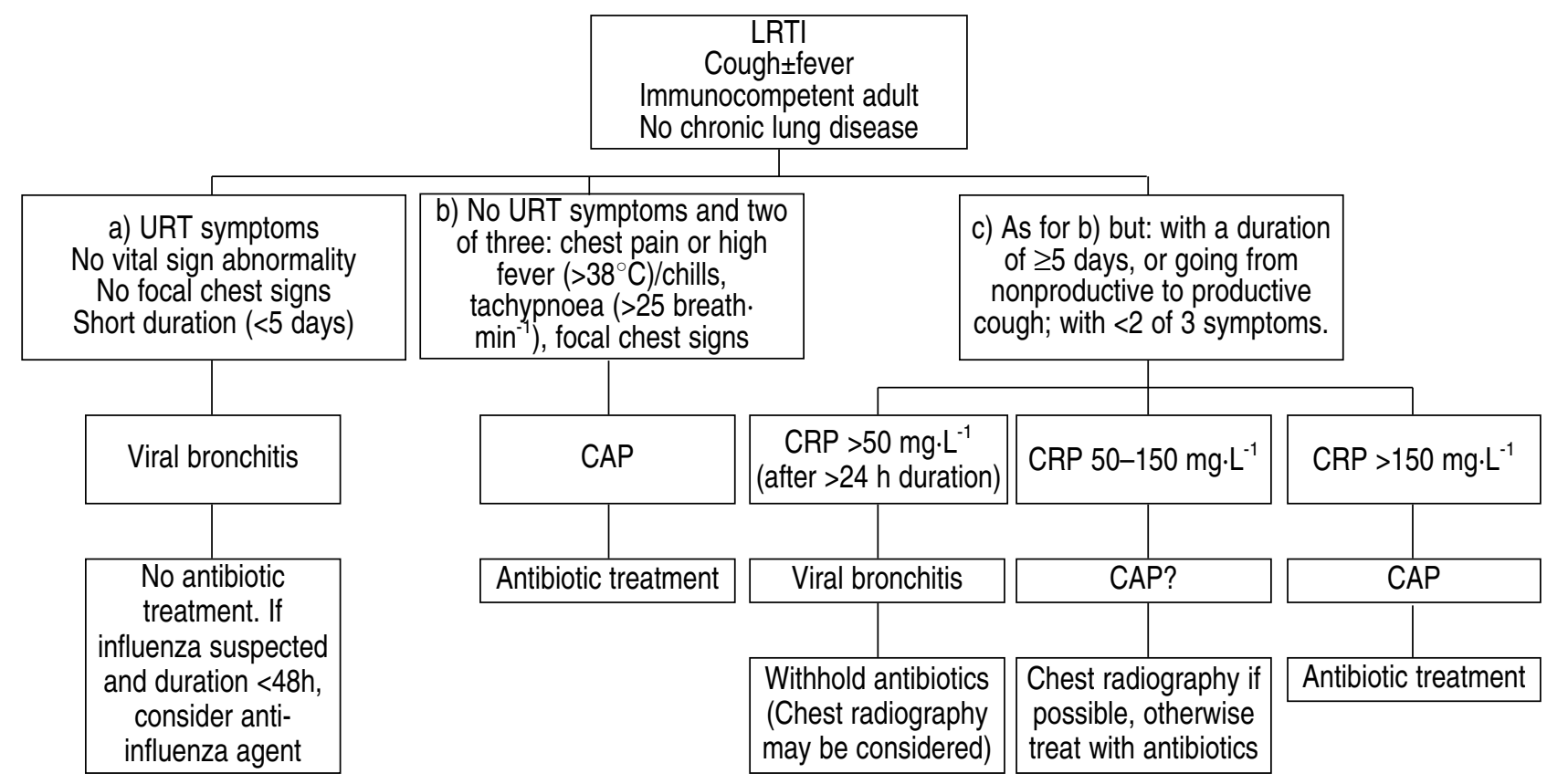

Fig. 1.-Suggested recommendations for differential diagnosis between acute bronchitis and community-acquired pneumonia (CAP) in an immunocompetent adult without chronic pulmonary disease. LRTI: lower respiratory tract infection; URT: upper respiratory tract; CRP: C-reactive protein.

S. pneumoniae and Haemophilus influenzae, thus making interpretation of its relative importance difficult.

Several studies have shown that clinical, laboratory and radiographic features cannot reliably differentiate between different causative pathogens [35]. However, epidemiological data, which have been included rarely in these analyses, may be of substantial help in the diagnosis of "atypical" agents, by, for example, identifying similar cases among family or friends or exposure to aerosolised freshwater in areas in which legionella infections commonly occur or just by the time of the year [31]. In addition, there are differences in the clinical presentation between a pneumococcal and an "atypical" pneumonia, especially if the latter is caused by $M$. pneumoniae, such as insidious onset, nonproductive cough and less systemic symptoms, that, taken together with the age of the patient, may be of help in making an "educated guess" concerning the aetiology of CAP in the individual patient [36-38].

A study from the USA advocating that the use of macrolides as part of the initial treatment for CAP shortens the length of stay (LOS), may instead support the view that physicians are able to use educated guesses to identify "atypical" pneumonia [39]. This was a small uncontrolled study in a hospital in which local guidelines recommended ceftriaxone for the treatment of CAP, but the addition of a macrolide if an "atypical" form was suspected. Of 76 evaluable patients, 12 were given a macrolide within the first $24 \mathrm{~h}$ (11 of these were also given a $\beta$-lactam) and the LOS in this group was significantly shorter than in CAP patients receiving only a $\beta$-lactam, or when a macrolide was added at a later stage. However, in the group of patients receiving macrolides within the first $24 \mathrm{~h}$, a pathogen was identified in only 1 of $12(8 \%)$, compared to in 23 of $64(36 \%)$ of those in the nonmacrolide group. This would indicate that, in the macrolide group, cultures were not performed because the doctor suspected an "atypical" aetiology, or that cultures turned out to be negative because of an "atypical" aetiology of CAP.

Further, in a recent prospective randomised study comparing amoxicillin/clavulanic acid with ceftriaxone for the treatment of CAP in Spain, one of the exclusion criteria was a strong clinical suspicion of legionella, atypical or viral pneumonia [40]. After randomisation, only 18 of $378(5 \%)$ patients were excluded because of one of these aetiological diagnoses, and nearly $90 \%$ of the patients in both treatment arms were cured according to the end of therapy assessment. Other European studies have shown that oral $\beta$-lactams alone are effective in the treatment of patients with LRTI, including radiographically verified CAP, both in the community and in the hospital setting [41, 42].

Swedish guidelines for the empirical treatment of mild-to-moderate CAP, although $10 \mathrm{yrs}$ old, are based on the possibility of distinguishing between "classic bacterial" pneumonia and "atypical" pneumonia using clinical, epidemiological and laboratory data [43]. In a retrospective survey of 1,042 randomly selected patients with CAP admitted to Swedish infectious diseases departments in 1995, the first-line treatment was penicillin alone $(45 \%)$ or a cephalosporin $(28 \%)$, and macrolides were prescribed to only $5 \%$ [43]. The total inhospital mortality was $2.6 \%$ and the LOS 6 days (mean). A new survey of 1,541 patients, in 1997, showed very similar results, with a single $\beta$-lactam as the first-line treatment in $\sim 75 \%$ of cases, and macrolides given as empirical treatment 
alone in only $5 \%$ and in combination with a $\beta$-lactam in $2 \%$ (unpublished data). Also, the LOS and inhospital mortality were comparable to the findings in 1995.

The question of the need to cover "atypical" agents in all patients was also recently raised in a study from the USA [44]. In this prospective study, an atypical agent was found in only 29 of $385(7.5 \%)$ adults, and a second pathogen was also identified in more than half of these cases. Moreover, a macrolide or tetracycline were given to only four of 29 patients, and none of the 29 patients died.

Finally, if "atypical" agents were to play a significant role in the overall outcome of pneumonia, this should have been observed in comparative antibiotic studies (although these have been powered mainly to show equivalence rather than superiority). However, with a few exceptions $[45,46]$, the outcome of patients treated with $\beta$-lactams alone have been comparable to that of those who have received macrolides or quinolones [47-54].

Taken together, these data indicate that there is no need to include treatment for atypical agents for all patients with CAP. Such treatment can be reserved for those for whom there is a strong clinical suspicion of such disease (e.g. CAP patients from geographical areas in which Legionnaires' disease occurs very frequently) and the severely ill patient (for whom broad coverage is necessary since the "cost" of administering the wrong antibiotic may be death).

\section{What is the local antimicrobial resistance situation?}

For some pathogens, the resistance situation seems to be similar all over the world. This is the case for Moraxella catarrhalis, which in almost all cases produces $\beta$-lactamases, and for "atypical" pathogens, such as mycoplasma, chlamydia or legionella, for which there are no problems with acquired resistance. However, for $S$. pneumoniae and $H$. influenzae, the risk for antimicrobial resistance in communityacquired LRTI pathogens varies both from country to country and within countries. It is therefore important to have a knowledge of local resistance data, and that these data are regularly updated. For $H$. influenzae, the $\beta$-lactamase production rate ranges $10-40 \%$, resulting in amoxicillin alone being a good choice in some countries, whereas combination with a $\beta$-lactam inhibitor, e.g. clavulanic acid, must be used in others. For $S$. pneumoniae, decreased susceptibility to penicillin is found in $<5->50 \%$ of the population, depending on the geographical area, type of sample (e.g. blood or nasopharyngeal secretions) and the population sampled [55]. However, even in areas with a high rate of intermediately or "highly" resistant pneumococci, penicillin or amoxicillin can still reliably be used as the first-line therapy of a pneumococcal LRTI. This statement is based on the following facts: 1) In areas in which penicillin resistance has been present for many years, the minimum inhibitory concentration of antibiotic (MIC) inhibiting 90\% of bacterial strains (MIC90) is still $1 \mathrm{mg} \cdot \mathrm{L}^{-1}$, and MIC of $>4 \mathrm{mg} \cdot \mathrm{L}^{-1}$ are extremely rare $[40,55,56] ; 2$ ) With high-dose penicillin or amoxicillin, adequate concentrations at the site of infection are achieved even when treating highly resistant (MIC $\leqslant 4 \mathrm{mg} \cdot \mathrm{L}^{-1}$ ) pneumococci [57]; 3) To date, studies of pneumonia treated with penicillins or other $\beta$-lactams, adjusted for underlying factors and severity of illness, have shown a similar and favourable outcome in patients in whom the infection was caused by penicillin-resistant strains to that in infections caused by penicillinsensitive strains [40, 55, 58-61]; 4) Among pneumococci with decreased susceptibility to penicillin (MIC $\left.\geqslant 0.1 \mathrm{mg} \cdot \mathrm{L}^{-1}\right)$, there is a significant coresistance to common alternative antimicrobial agents, such as other $\beta$-lactams, erythromycin, clindamycin, tetracycline and trimethoprim/sulfamethoxazole [40, 56, 62]. For macrolides, the rate of coresistance increased during the last part of the 1990s. In some centres, the prevalence of $S$. pneumoniae macrolide resistance exceeds that of penicillin resistance, and a correlation between increasing macrolide resistance and the increased use of newer long-acting macrolides has been indicated [24]. The level of macrolide resistance is often very high, making it impossible to overcome by increasing the dosage, and failures have been reported using macrolides as single therapy for CAP [63]. It should also be pointed out that amoxicillin is more active against resistant pneumococci than any of the available oral cephalosporins, and that overuse of the latter may also be an important driving force for $\beta$-lactam resistance [24].

Usefulness of the new respiratory quinolones and other novel antibiotics

Older quinolones, such as ciprofloxacin and ofloxacin, have rather poor antipneumococcal efficacy and are not recommended for the empirical treatment of CAP. During the 1990s, however, fluoroquinolones (FQs) with an extended Gram-positive spectrum were developed, which have been shown in randomised trials to have a high cure rate, equal to, or sometimes better than, that of drugs to which they have been compared [13]. Unfortunately, several of the new FQs (temafloxacin, sparfloxacin, grepafloxin, trovafloxacin, and clinafloxacin) were withdrawn shortly after, or even before, they were introduced due to safety problems. Of those remaining, levofloxacin (an L-isomer of ofloxacin) is available in most countries, whereas moxifloxacin and gatifloxacin are on the way to market or only licensed in some countries. Whereas the MIC90 for $S$. pneumoniae of levofloxacin is $\sim 1 \mathrm{mg} \cdot \mathrm{L}^{-1}$, it is generally $\leqslant 0.25 \mathrm{mg} \cdot \mathrm{L}^{-1}$ for the two newer FQs, which, therefore, are sometimes called "respiratory" FQs.

The respiratory FQs have some definite advantages. They exhibit broad spectrum coverage including all common LRTI pathogens, high bioavailability, good penetration resulting in high intracellular concentrations, a long half-life permitting once or twice daily dosing, and are rapidly bactericidal. However, their broad spectrum of activity and common use against many other infections is also a concern, since widespread use of this class of antibiotics may lead to a rapid increase in already emerging resistance problems 
[14]. Resistance to quinolones evolves in a stepwise fashion and a single mutation may be enough for resistance to older FQs, whereas an additional mutation (or mutations) is needed for development of resistance to the newer FQs.

An increase in the use of FQs associated with development of resistance has been reported in several geographical areas, e.g. Canada, Spain and Hong Kong [64-66]. In Canada, ciprofloxacin resistance among pneumococcal isolates increased from 1.5 to $2.9 \%$ between 1993 and 1998, and was highest among elderly persons, which correlated to the degree of usage of these drugs [64]. An even more dramatic increase has been documented in Hong Kong, where resistance in pneumococci (MIC $\geqslant 4 \mathrm{mg} \cdot \mathrm{L}^{-1}$ ) was very low in $1995,<0.5 \%$ for ofloxacin, but had risen to $12.1 \%$ for ciprofloxacin, $5.5 \%$ for levofloxacin and $2.2 \%$ for trovafloxacin in 1998 [66]. Four of the pneumococcal strains from the Hong Kong study were resistant to penicillin with MICs of $1-3 \mathrm{mg} \cdot \mathrm{L}^{-1}$, erythromycin with MICs of $2-6 \mathrm{mg} \cdot \mathrm{L}^{-1}$ and quinolones with MICs of $>32 \mathrm{mg} \cdot \mathrm{L}^{-1}$ for ciprofloxacin and levofloxacin and of 2,16 and $>32 \mathrm{mg} \cdot \mathrm{L}^{-1}$ for trovafloxacin. Thus, all four strains could have been treated with high-dose penicillin, but only one with trovafloxacin and none with erythromycin. Clinically, the risk of failure of ciprofloxacin in the treatment of pneumococcal infections has been known since the beginning of the 1990s [67, 68], but now reports of levofloxacin failures are also beginning to be made [69]. In addition, a clinical failure on trovafloxacin in a patient with bacteraemic pneumococcal pneumonia (MIC for trovafloxacin $8 \mathrm{mg} \cdot \mathrm{L}^{-1}$ ) has been reported recently [70].

Thus, it may be wise not to use respiratory FQs as a first-line therapy for LRTI, but to reserve these drugs for selected patients with CAP [14]. Examples of such patients are those who have a documented infection with highly resistant pneumococci (MIC $>4 \mathrm{mg} \cdot \mathrm{L}^{-1}$ ) or Legionella spp., are allergic to alternative agents, have failed using a first-line regimen, or are severely ill and in need of ICU treatment, where a FQ may be one of the alternatives for combination together with a $\beta$-lactam. However, it should be pointed out that, when a quinolone is indicated, one of the new respiratory FQs should be used, since they are less likely to induce development of resistance than the older ones.

Among other new antibiotics, two groups are of special interest in the treatment of LRTIs, the oxazolidones and ketolides. One substance from the former group, linezolid, has now been licensed in several countries. Linezolid is a strictly Grampositive antibiotic which is active also against highly penicillin-resistant pneumococci and other resistant Gram-positive organisms that may be difficult to treat, such as methicillin-resistant Staphylococcus aureus and vancomycin-resistant enterococcus [71]. The role of linezolid in the treatment of community LRTI remains to be established, but it will probably be useful mainly as a second-line treatment for documented infections with resistant pneumococci. Conversely telithromycin, the first of the ketolide antibiotics, which is on the way to being licensed in some countries, may be a potential choice in the empirical therapy of CAP. Although derived chemically from the macrolides it provides potent activity against both common "atypical" pathogens and common LRTI bacteria, including those resistant to $\beta$-lactams and macrolide/lincosamide/streptogramin $\mathrm{B}$ antibiotics [72]. In three randomised double-blind comparator studies of mild-to-moderate CAP, the clinical success rate of telithromycin was $>90 \%$ and demonstrated equivalence to amoxicillin, clarithromycin and trovafloxacin [73].

\section{Assessment of severity of illness and need for hospital admission}

The need for hospital admission is often, but not always, due to the severity of illness. Inability to maintain gas exchange or a stable circulation are obvious markers of severe disease, whereas absence of adequate nursing and social support mechanisms as well as inability to maintain fluid intake, may reflect either severe illness, age and/or underlying conditions.

Unfortunately, there is as yet no single severity assessment that can simply and reliably predict whether or not a patient needs hospital treatment, or the outcome of a LRTI. In order to be of value in the outpatient setting, a severity assessment should be based only on symptoms and signs. In 1993, the British Thoracic Society (BTS) formulated a CAPspecific prognostic formula in which one of the two discriminant rules relied only on bedside observation [8]. This rule, which was based on patients aged 1874 yrs treated in hospital for CAP, included the presence of a respiratory frequency of $\geqslant 30 \mathrm{breaths} \cdot \mathrm{min}^{-1}$, a diastolic blood pressure of $\leqslant 60 \mathrm{mmHg}$ and confusion. The presence of two of these three criteria was associated strongly with death, but the sensitivity and positive predictive value of both this and the second rule, in which confusion was exchanged for a blood urea concentration of $>7 \mathrm{mM}$, was low. Recent validations of both the original BTS rule and a slightly modified version of this rule also showed that they performed poorly, especially in patients aged $\geqslant 75 \mathrm{yrs}$ $[74,75]$. In a much more complicated prediction rule, derived and validated using two different large samples of CAP patients in the USA, the first class (risk class I) is based on clinical information alone, whereas stratification of risk classes II-V requires radiological and laboratory data [76]. Patients belonging to risk class I were aged $\leqslant 50$ yrs, did not have underlying diseases or alterations in vital signs, and showed a very low mortality $(0.1-0.4 \%)$. Mortality was also low in risk classes II and III (0.6-0.7 and $0.9-2.8 \%$, respectively), but increased steeply to $9.3 \%$ in risk class IV and $27 \%$ in risk class V. Thus, it has been suggested that patients in the lowest risk classes (I and II) can safely be treated as outpatients, whereas those in class III may need a brief stay in hospital $[12,13]$. However, it should be noted that these predictive scores are based on groups of patients, and may not always be applicable in the individual patient [77, 78]. Social factors should also be considered. Further, age plays a dominant role in the final score, which must be kept in mind when evaluating young 
persons with CAP. In addition, some "classical" negative prognostic factors are not included in this score, such as leucopenia, alcoholism or multilobar pneumonia. Thus, a 20-yr-old female with a 1-day history of fever and cough, who is found to have multilobar radiographic changes but without pleural fluid, a respiratory frequency of 40 breaths $\cdot \mathrm{min}^{-1}$ and an oxygen saturation of $80 \%$ on room air, would be classified as a low-risk patient (class II). Similarly, a 55-yr-old alcoholic male, presenting with bilateral pneumonia, leucopenia, a respiratory frequency of 25 breaths $\cdot \min ^{-1}$ and an oxygen saturation of $85 \%$, would also rank as a low risk patient (class II). Few doctors would let either of these two patients leave with just an antibiotic prescription.

Identifying severely ill CAP patients with a possible need for ICU treatment is also difficult. Undoubtedly, patients meeting the criteria of the BTS rule may be candidates for ICU treatment. The revised criteria of the American Thoracic Society (ATS) for "severe CAP" may be helpful [15]. The ATS rule is based on the presence of at least one major criterion (need for mechanical ventilation, an increase in the size of infiltrates by $>50 \%$ within $48 \mathrm{~h}$, septic shock or the need for vasopressors for $>4 \mathrm{~h}$, and acute renal failure) or two minor criteria (respiratory frequency $\geqslant 30$ breaths $\cdot \mathrm{min}^{-1}$, arterial oxygen tension/inspiratory oxygen fraction $<250$, bilateral/multilobar pneumonia, systolic blood pressure $\geqslant 90 \mathrm{mmHg}$ and diastolic blood pressure $\leqslant 60 \mathrm{mmHg}$ ). Finally, the Acute Physiology, Age, and Chronic Health Evaluation II score has been shown to clearly identify those at risk of dying from pneumococcal bacteraemic pneumonia $[20,79]$.

Thus, the major difficulty in severity assessment lies in the identification of those LRTI patients who are neither the least nor the most severely ill, those who are likely to need hospital treatment. The present author's recommendations for when patients should generally be admitted to hospital are shown in table 1 .

\section{Treatment of lower respiratory tract infection}

\section{Acute bronchitis}

As discussed above, acute bronchitis is most often a viral disease, and antibiotics should be avoided [12]. In a review of nine double-blind placebo-controlled studies, no advantage for antibiotics (doxycycline or erythromycin) was found in seven, whereas antibiotics (erythromycin and trimethoprim/sulfamethoxazole) were slightly better than placebo in two [80]. In addition, two of these studies showed that bronchodilators were superior to antibiotics in reducing cough and other symptoms. In a recent Cochrane review, a slight benefit of antibiotics was noted, but not in patients who also had symptoms of common cold and had been ill for $<1$ week [81]. Furthermore, this slight benefit was balanced by an increase in adverse effects using antibiotics.
Table 1.-Medical risk factors in patients with acute community-acquired lower respiratory tract infection indicating probable benefit from admission to hospital ${ }^{\#}$

\section{History}

High age

Immunocompromising illness or treatment

Previous splenectomy

Uncontrolled coexisting illness

Alcohol abuse and/or malnutrition

Physical findings

Acute altered mental status

Systolic BP $<90 \mathrm{mmHg}$ or diastolic $\mathrm{BP}<60 \mathrm{mmHg}$

Respiratory frequency $>30$ breaths $\cdot \mathrm{min}^{-1}$

Laboratory findings

$\mathrm{Sa}_{\mathrm{a}, \mathrm{O}_{2}}<90 \%$, or $\mathrm{Pa}, \mathrm{O}_{2}<8 \mathrm{kPa}$, on room air

Multilobar pneumonia

Pleural effusion $(>1 \mathrm{~cm}$ on lateral decubitus chest radiograph)

Suspected lung abscess

Acute renal failure (urea $>7 \mathrm{mM}$ or creatinine $\left.>120 \mathrm{mg} \cdot \mathrm{L}^{-1}\right)$

Leucopenia $\left(<4 \times 10^{9}\right.$ cells $\left.\cdot \mathrm{L}^{-1}\right)$

Severe anaemia (haematocrit $<30 \%$ )

Hypoalbuminaemia $\left(<25 \mathrm{~g} \cdot \mathrm{L}^{-1}\right)$

BP: blood pressure; $\mathrm{Sa}_{2} \mathrm{O}_{2}$ : arterial oxygen saturation; $\mathrm{Pa}, \mathrm{O}_{2}$ : arterial oxygen tension. ${ }^{\#}$ : any one of these indicates probable benefit; ": no specific age limit can be given as it depends on biological rather than chronological age.

Acute exacerbation of chronic bronchitis/chronic obstructive pulmonary disease

Chronic bronchitis is defined as productive cough for $\geqslant 3$ months $\mathrm{yr}^{-1}$ during $\geqslant 2$ consecutive yrs, whereas the term chronic obstructive pulmonary disease (COPD) is used to describe several pathophysiological entities characterised by airflow obstruction, including chronic bronchitis, but also emphysema, asthma and bronchiectasis [82]. The clinical distinction between these entities is not always clear, but, in the following, the focus is on patients who have acute exacerbations of COPD associated with chronic bronchitis or emphysema (AE-CB/COPD). There is no widely accepted definition of AE-CB/COPD, but most include one or more of three cardinal findings: worsening dyspnoea, increase in sputum purulence, and increase in sputum volume [83].

Bacteria can be isolated from sputum in $\sim 50 \%$ of cases of $\mathrm{AE}-\mathrm{CB} / \mathrm{COPD}$, but whether this represents bronchial colonisation or infection has long been a controversial issue [84]. The problem of how to interpret cultures from the lower respiratory tract is well illustrated by two studies using bronchoscopy with protected specimen brush to obtain uncontaminated samples, one in 18 stable COPD patients and the other in 54 patients with severe AE-CB/COPD requiring ICU treatment $[85,86]$. Significant growth of bacteria $\left(\geqslant 10^{3}\right.$ colony-forming units $\left.(\mathrm{cfu}) \cdot \mathrm{mL}^{-1}\right)$ was found in $44 \%$ of the ICU-treated patients, but also in $33 \%$ of the stable COPD patients, and with approximately the same spectrum of pathogens; $H$. influenzae or other Haemophilus species, S. pneumoniae, $M$. catarrhalis, $S$. aureus, and an occasional member of the Enterobacteriaceae or Pseudomonas aeruginosa. However, the one difference was that 
heavy growth of bacteria $\left(\geqslant 10^{5} \mathrm{cfu} \cdot \mathrm{mL}^{-1}\right)$ was found in $24 \%$ of the ICU-treated patients, i.e. more than half of those with a significant culture, but not at all among the stable patients (fig. 2). In another study, growth of pathogenic bacteria was found twice as often at a level of $\geqslant 10^{3} \mathrm{cfu} \cdot \mathrm{mL}^{-1}$ and four times as often at $\geqslant 10^{4} \mathrm{cfu} \cdot \mathrm{mL}^{-1}$ in patients with AE-CB/ COPD than in a control group [87], thus supporting a role for bacteria in a subset of $\mathrm{AE}-\mathrm{CB} / \mathrm{COPD}$. Accordingly, antibiotics have been found to be beneficial in selected patients with AE-CB/COPD $[82,88]$. The beneficial effect is more likely to occur in patients with severe rather than less severe AE-CB/ COPD. Severity can be assessed by using either clinical judgement or the criteria developed by N.R. Anthonisen [82]. According to the criteria of ANTHONisen et al. [89], a severe exacerbation (type 1) contains all three, and a moderate exacerbation (type 2) two of the three cardinal symptoms of an AE-CB/ COPD. Suggested recommendations for when antibiotic treatment should be considered are given in

a)

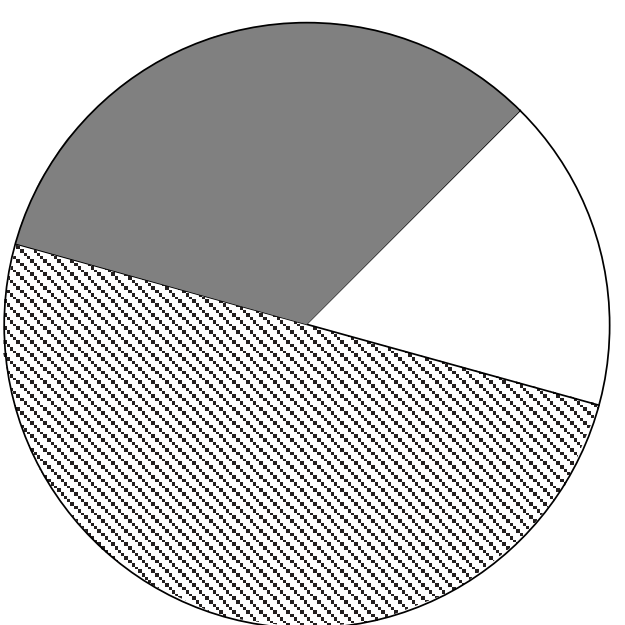

b)

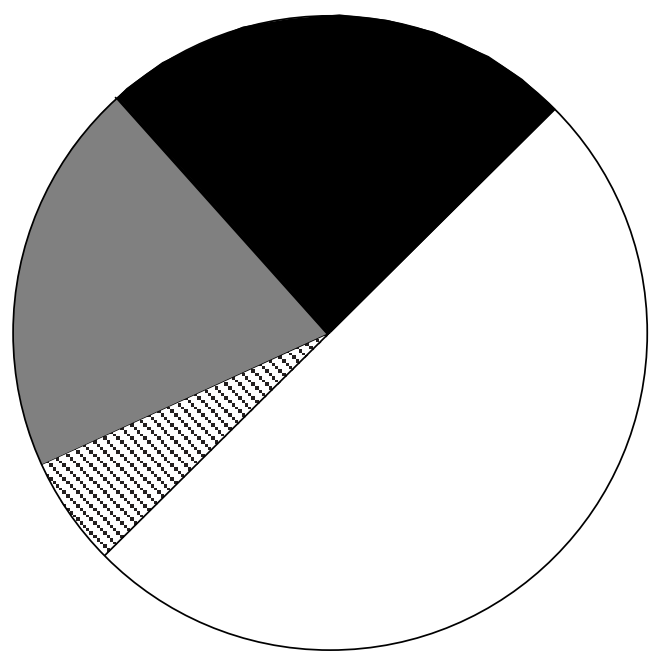

Fig. 2.-Bacterial growth in samples obtained using bronchoscopy and protected specimen brush in: a) 18 stable chronic obstructive pulmonary disease (COPD) patients [85]; and b) 54 patients with severe acute exacerbation of COPD requiring intensive care unit treatment and mechanical ventilation [86]. $\square$ : no growth; $\mathbb{\mathbb { N } :}<10^{3}$ colonyforming units $(\mathrm{cfu}) \cdot \mathrm{mL}^{-1} ; \mathbf{\square}: 10^{3}-10^{5} \mathrm{cfu} \cdot \mathrm{mL}^{-1} ; \mathbf{\square}: \geqslant 10^{5} \mathrm{cfu} \cdot \mathrm{mL}^{-1}$.
Table 2.-Indications for antibiotic treatment in acute exacerbations of chronic obstructive pulmonary disease

ANTHONISEN et al. [89] type 1, i.e. presence of worsening dyspnoea, increase in sputum purulence and increase in sputum volume

Presence of one or two of worsening dyspnoea, increase in sputum purulence and increase in sputum volume, plus systemic symptoms or findings such as high fever and CRP $>50 \mathrm{mg} \cdot \mathrm{L}^{-1}$

Severe illness characterised by severe underlying lung disease (FEV1 $<50 \%$ pred), frequent exacerbations $(\geqslant 4 \cdot \mathrm{yrs})$, advanced age, significant comorbidity, or need for intensive care unit treatment

CRP: C-reactive protein; FEV1: forced expiratory volume in one second; $\%$ pred: percentage of the predicted value.

table 2. Sputum culture is of limited value in outpatient treatment of nonsevere AE-CB/COPD. However, in patients with severe disease, cultures from sputum, or, if possible, on protected samples obtained bronchoscopically, may be of value if empirical treatment fails. The choice of antibiotics for empirical treatment is based on the spectrum of pathogens causing $\mathrm{AE}-\mathrm{CB} / \mathrm{COPD}$, the local resistance situation and the severity of illness. It is important to point out that all placebo-controlled antibiotic studies have been performed with "older" drugs, such as amoxicillin, tetracyclines and trimethoprim/sulfamethoxazole, and that there are so far no published randomised blinded studies showing a superiority of newer drugs, such as cephalosporins or quinolones [83]. H. influenzae, or other Haemophilus species, and S. pneumoniae are the most common and important pathogens, followed by $M$. catarrhalis, and should be the primary target of treatment (table 3 ). The role of atypical pathogens is even more questionable for patients with AE-CB/ COPD than for those with CAP and they need not routinely be covered. For more severely ill patients, or in those who have received repeated courses of antibiotics during recent months, broader treatment may be needed, including coverage against $S$. aureus, Enterobacteriaceae and, in patients known to have been colonised previously, $P$. aeruginosa. Oral treatment is, in most cases, adequate, but, in the severely ill, intravenous antibiotics may be necessary during the initial phase.

Table 3. - Empirical antibiotic treatment of acute exacerbations of chronic bronchitis/chronic obstructive pulmonary disease

\begin{tabular}{|c|c|c|}
\hline & First-line choice & Alternative choices $\#$ \\
\hline Nonseverely ill & $\begin{array}{l}\text { Amoxicillin } \pm \\
\text { clavulanic acid }\end{array}$ & $\begin{array}{l}\text { Doxycycline, } \\
\text { trimethoprim/ } \\
\text { sulfamethoxazole }\end{array}$ \\
\hline Severely ill & $\begin{array}{l}\text { Cefuroxime/ } \\
\text { cefotaxime/ } \\
\text { ceftriaxone } i . v ., \text { or } \\
\text { "respiratory" } \\
\text { fluoroquinolone }\end{array}$ & $\begin{array}{l}\text { Ceftazidime, } \\
\text { carbapenem, } \\
\text { or Ciproxin if } \\
\text { risk for or } \\
\text { documented } \\
\text { Pseudomonas } \\
\text { aeruginosa }\end{array}$ \\
\hline
\end{tabular}

\footnotetext{
\#: depending on allergies, local resistance patterns and cul-
} ture results. 


\section{Community-acquired pneumonia}

Ideally, initial antimicrobial treatment of CAP should be directed towards the specific pathogen causing the disease. However, few methods are available for rapid microbiological diagnosis, and the results of such tests are rarely at hand when antibiotic treatment is started. Thus, in most cases treatment has to be started in an empirical fashion.

Aetiological diagnosis. In most cases, no microbiological investigations are needed in the outpatient setting. However, in hospitalised patients, it is important to try to establish an aetiological diagnosis, to be able to switch to a specific treatment and to form the basis for treatment change in case of failure on empirical therapy. In the latter case, repeated diagnostic investigations should be performed before treatment is changed [90]. In a patient treated in a hospital ward, the sampling should include blood cultures, sputum if available for Gram staining and culture, and urine for antigenic detection of Legionella pneumophila if there is an epidemiological or clinical suspicion of legionellosis. Urine may also be analysed for pneumococcal antigen, and, if present, pleural fluid should be sent for culture. In the severely ill patient requiring ICU treatment, invasive diagnostic methods, preferably fibreoptic bronchoscopy with protected brush specimen and bronchoalveolar lavage, should also be considered. Lower respiratory tract samples obtained by bronchoscopy should be analysed using aerobic and anaerobic culture, and with cultures and/or immunological methods for legionella, viruses, mycoplasma, chlamydia, Pneumocystis carinii, and sometimes also other fungi.

Community-acquired pneumonia guidelines. As noted above, four North American sets of guidelines for the management of CAP were published in 2000 and 2001 [12-15]. The empirical antibiotic treatment recommended by these is summarised in table 4, together with the recommendations of the European Respiratory Society, published in 1998 [10], in order to obtain some balance across the Atlantic. Why then have guidelines? The rationale for guidelines is that CAP is a common and serious disease, involving multiple aetiological agents and an evolving resistance problem. Further, despite extensive studies there are few conditions that are so controversial in terms of management. During work on guidelines, information from hundreds of studies is synthesised and evaluated, and the final recommendation forms a basis for a uniform approach to empirical treatment of CAP. The need for guidelines and a policy to achieve a more uniform approach towards empirical treatment, may vary from country to country, from hospital to hospital and department to department. A study comparing bacteraemic pneumococcal pneumonia in Sweden and the USA from the time before pneumococcal resistance was a cause of concern in the latter country, may serve as an example of varying antibiotic practices [91]. In this study, the empirical therapy of CAP in the USA and Swedish patients, respectively, was penicillin or ampicillin in 34 versus $83 \%$, a cephalosporin in 29 versus $6 \%$, an aminoglycoside in 20 versus $3 \%$ and two or more drugs in 37 versus $5 \%$. Since combination treatment is still infrequently used in Sweden for empirical inhospital treatment of CAP (see above), implementation of North American guidelines, recommending both a $\beta$-lactam and a macrolide, or a respiratory quinolone, would lead to overuse of antibiotics in Sweden. The same effect would be seen in several other European countries. Another possible negative effect of using and relying on guidelines for the management of CAP may be that doctors stop trying to evaluate the available clinical data in a critical way. To follow an algorithm may be easier, but could lead to the wrong decision, since no guideline covers all variations in patient presentation, and no antibiotic covers all microbial causes of CAP. Even using a set of guidelines may be difficult. The first question is which one to use? One author contributed to the formulation of three of the North American sets of guidelines published in 2000 and 2001 [12, 13, 15], and four authors contributed to two of the three. However, the recommendations of these three sets of guidelines differ significantly. The second question is whether the guidelines have been validated. They have, but the results of these studies are not consistent, especially where antibiotic treatment is concerned. The major bias, lowering the strength of the evidence of all of these studies, is that the choice of empirical antimicrobial therapy has not been controlled for, i.e. the reason why a specific person was prescribed a certain empirical drug is unknown. This should be kept in mind when interpreting the favourable results of these studies, indicating that the implementation of guidelines may lead to reduced cost, reduced length of stay and reduced mortality, at least in the USA. In one prospective cohort study on nearly 900 outpatients with CAP [92], the cost of antibiotic treatment in patients aged $\leqslant 60$ yrs was lower if antimicrobial therapy was consistent rather than inconsistent with the 1993 ATS guidelines [7]. Conversely, for patients aged $>60$ yrs or with some comorbidity, use of guidelines resulted in more extensive antibiotic treatment without an improved medical outcome. In another retrospective study, using Cox regression analysis of the medical records of nearly 13,000 patients aged $\geqslant 65$ yrs treated in hospital with CAP, treatment with a second- or third-generation cephalosporin plus macrolide, or an FQ alone, was associated with lower 30-day mortality than in the reference group (third-generation cephalosporin alone) [93]. Use of $\beta$-lactam/ $\beta$-lactamase inhibitor plus macrolide or an aminoglycoside plus another agent was associated with a higher 30-day mortality. Strangely enough, the use of $\beta$-lactam/ $\beta$-lactamase inhibitor alone was not associated with higher mortality, and, again, it was not possible to control for why the various specific treatments had been chosen. In a third study, discussed above, the use of macrolides as part of the initial treatment of CAP was found to shorten the LOS [39]. However, this result may well have been the effect of doctors' ability to identify patients with "atypical" and less severe pneumonia. In a fourth retrospective study, a varying impact of specific antibiotic therapy on the 30-day mortality in $\sim 10,000$ patients aged $\geqslant 65$ yrs treated in hospital 
Table 4. - Recent guidelines for antibiotic treatment of community-acquired pneumonia

\begin{tabular}{|c|c|c|c|}
\hline Guidelines [Ref.] & Modifying factors/comments & First choice & Alternatives \\
\hline \multicolumn{4}{|l|}{ Outpatients } \\
\hline ERS [10] & LRTI $^{\#}$ & Aminopenicillin & $\begin{array}{l}\text { Tetracyclines, cephalosporins, } \\
\text { respiratory quinolones, } \\
\text { streptogramins, macrolides }\end{array}$ \\
\hline \multirow[t]{3}{*}{ Canadian [13] } & No modifying factor & Macrolide & Doxycycline \\
\hline & $\begin{array}{l}\text { COPD, no recent antibiotics } \\
\text { or oral steroids }\end{array}$ & New macrolide & Doxycycline \\
\hline & $\begin{array}{l}\text { COPD, antibiotics or oral } \\
\text { steroids within } 3 \text { months }\end{array}$ & Respiratory FQ & $\begin{array}{l}\text { Co-amoxiclav 2nd } \\
\text { GEN cephalosporin }+ \\
\text { macrolide }\end{array}$ \\
\hline IDSA [12] & & Doxycycline/macrolide/FQ ${ }^{+}$ & \\
\hline $\mathrm{CDC}[14]$ & & $\begin{array}{l}\text { Macrolide/doxycycline/ } \\
\text { cefuroxime/co-amoxiclav }\end{array}$ & Respiratory FQ \\
\hline \multirow[t]{2}{*}{ ATS [15] } & No modifying factor & New macrolide & Doxycycline \\
\hline & $\begin{array}{l}\text { Cardiopulmonary disease } \\
\text { or other modifying factor }\end{array}$ & $\begin{array}{l}\beta \text {-Lactam }+ \text { macrolide } \\
\text { or doxycycline }\end{array}$ & Respiratory FQ \\
\hline \multicolumn{4}{|l|}{$\begin{array}{l}\text { Hospital treated - } \\
\text { general ward }\end{array}$} \\
\hline ERS [10] & & $\beta$-Lactam \pm macrolide & \\
\hline Canadian [13] & & Respiratory FQ & $\begin{array}{l}\text { 2nd-4th GEN } \\
\text { cephalosporin+ } \\
\text { macrolide }\end{array}$ \\
\hline IDSA [12] & & $\beta$-Lactam \pm macrolide & FQ \\
\hline CDC [14] & & $\beta$-Lactam \pm macrolide & $\mathrm{FQ}$ \\
\hline \multirow[t]{2}{*}{ ATS [15] } & No modifying factor & Azithromycin i.v. & $\begin{array}{l}\beta \text {-Lactam }+ \text { doxycycline } \\
\text { or FQ alone }\end{array}$ \\
\hline & $\begin{array}{l}\text { Cardiopulmonary dis or } \\
\text { other modifying factor }\end{array}$ & $\begin{array}{l}\beta \text {-Lactam }+ \text { doxycycline } \\
\text { or macrolide }\end{array}$ & FQ \\
\hline \multicolumn{4}{|l|}{ ICU-treatment } \\
\hline ERS [10] & & $\begin{array}{l}\text { 2nd-3rd GEN cephalosporin+ } \\
\text { macrolide or } F Q \pm \text { rifampicin }\end{array}$ & \\
\hline \multirow[t]{2}{*}{ Canadian [13] } & P. aeruginosa not suspected & Respiratory $\mathrm{FQ}+\beta$-lactam & $\beta$-Lactam + macrolide \\
\hline & $P$. aeruginosa suspected & $\begin{array}{l}\text { Ciprofloxacin+antipseudomonal } \\
\beta \text {-lactam or AG }\end{array}$ & $\begin{array}{l}\text { Antipseudomonal } \\
\beta \text {-Lactam }+A G+\text { macrolide }\end{array}$ \\
\hline \multirow[t]{2}{*}{ IDSA [12] } & P. aeruginosa not suspected & $\begin{array}{l}\text { Extended spectrum } \\
\beta \text {-lactam }+\mathrm{FQ} \\
\text { or macrolide }\end{array}$ & \\
\hline & Structural lung disease & $\begin{array}{l}\text { Antipseudomonal } \\
\beta \text {-lactam+ciprofloxacin }\end{array}$ & \\
\hline \multirow{3}{*}{$\begin{array}{l}\text { CDC [14] } \\
\text { ATS [15] }\end{array}$} & & $\beta$-Lactam + macrolide or FQ & Respiratory FQ \\
\hline & P. aeruginosa not suspected & $\beta$-Lactam + macrolide or FQ & \\
\hline & $P$. aeruginosa suspected & $\begin{array}{l}\text { Antipseudomonal } \\
\beta \text {-lactam+ciprofloxacin }\end{array}$ & $\begin{array}{l}\text { Antipseudomonal } \\
\beta \text {-lactam }+ \text { AG+respiratory } \\
\text { FQ or macrolide }\end{array}$ \\
\hline
\end{tabular}

ERS: European Respiratory Society; IDSA: Infectious Diseases Society of America; CDC: Centers for Disease Control and Prevention; ATS: American Thoracic Society; LRTI: lower respiratory tract infection; FQ: fluoroquinolone; GEN: generation; P. aeruginosa: Pseudomonas aeruginosa; AG: aminoglycoside. \#: no distinction was made between communityacquired pneumonia and other LRTIs; ${ }^{+}$: depending on local resistance situation and underlying factors; ${ }^{\S}$ : risk factors for penicillin-resistant pneumococci or Gram-negative bacteria; ${ }^{f}$ : risk factors for penicillin-resistant pneumococci or Gramnegative bacteria, including nursing home patients.

with CAP was found during three different years, 1993, 1995 and 1997 [94]. During these 3 yrs, the use of a $\beta$-lactam alone decreased from 57 to $49 \%$, whereas the use of a combination of a $\beta$-lactam plus a macrolide increased from 10 to $25 \%$. Macrolide monotherapy and FQ monotherapy were each used in only $1-2 \%$ of cases during all 3 yrs. In 1993, but not in 1995 or 1997, a combination of $\beta$-lactam plus macrolide was associated with lower mortality than with a $\beta$-lactam alone. Thus, this may reflect the fact that in 1993, before the first guidelines were implemented, macrolides were added mainly on the suspicion of atypical pneumonia, a patient group with a low mortality.
Two studies, from Canada and the USA, offer the most convincing evidence that implementation of guidelines or critical pathways for the treatment of CAP may lead to both health and economic benefits $[95,96]$. However, it is not possible to evaluate the role of antimicrobial treatment per se, since the whole process of care was studied, including clinical prediction rule for admission decision, choice of empirical antibiotics and practice guidelines.

Suggested strategy for empirical treatment of communityacquired pneumonia. The present author's personal view regarding the empirical therapy of CAP in 


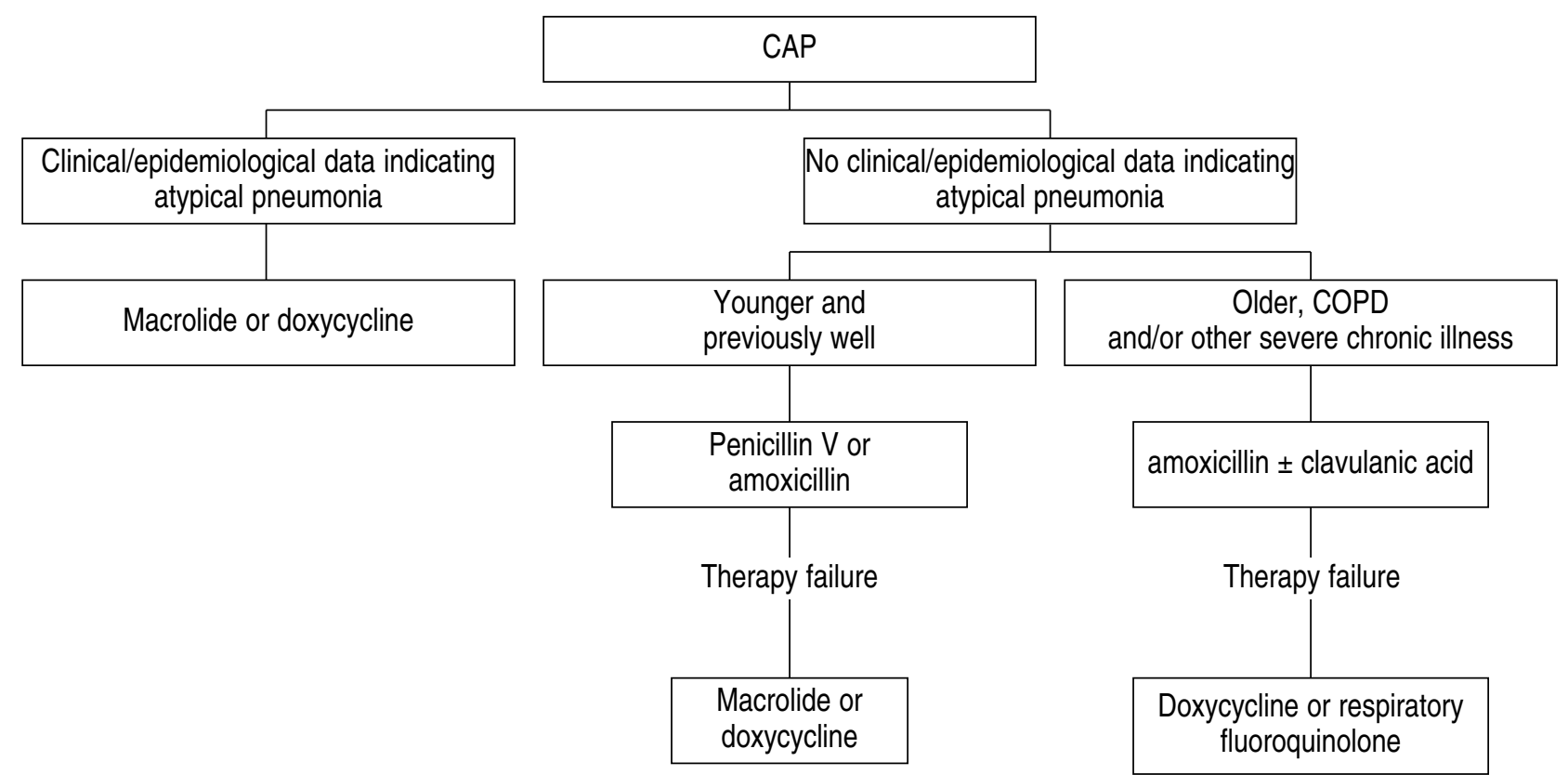

Fig. 3. - Suggested strategy for empirical outpatient treatment of community-acquired pneumonia (CAP) in the immunocompetent adult. COPD: chronic obstructive pulmonary disease.

outpatients is shown in figure 3 and for inhospital treatment in table 5. As can be seen, this strategy is based on severity of illness plus the "most likely pathogen" in various patient categories. Using this strategy, most nonsevere patients would receive monotherapy, most often with a $\beta$-lactam alone. This $\beta$-lactam should be penicillin or amoxicillin \pm clavulanic acid (oral or i.v.), or a second- or third-generation

Table 5.-Suggested strategy for empirical inhospital treatment of community-acquired pneumonia (CAP) in the immunocompetent adult

\begin{tabular}{|c|c|c|}
\hline Patient category & $\begin{array}{l}\text { Probable pathogen } \\
\text { (cover required) }\end{array}$ & Choice of empirical therapy \\
\hline \multicolumn{3}{|l|}{ Mild to moderate CAP } \\
\hline All cases & Streptococcus pneumoniae & $\begin{array}{l}\text { Benzylpenicillin or amoxicillin } \pm \text { clavulanic acid } \\
\text { Cefotaxime/ceftriaxone if high rate of highly } \\
\text { penicillin-resistant pneumococci }\end{array}$ \\
\hline $\begin{array}{l}\text { Chronic pulmonary disease } \\
\text { or post-influenza pneumonia }\end{array}$ & $\begin{array}{l}\text { Haemophilus influenzae and } \\
\text { Moraxella catharralis }\end{array}$ & $\begin{array}{l}\text { Co-amoxiclav, or } 2 \mathrm{nd} / 3 \text { rd generation } \\
\text { cephalosporin (i.v.) }\end{array}$ \\
\hline $\begin{array}{l}\text { Postinfluenza pneumonia and } \\
\text { drug addicts }\end{array}$ & Staphylococcus aureus & 2nd/3rd generation cephalosporin (i.v.) \\
\hline $\begin{array}{l}\text { Epidemiological/clinical data } \\
\text { indicating legionella }\end{array}$ & Legionella & $\begin{array}{l}\text { Respiratory } \mathrm{FQ} \text {, or macrolide }+ \\
\text { benzylpenicillin/amoxicillin } \pm \text { clavulanic, } \\
\text { or } 2 \text { nd/3rd generation cephalosporin (i.v.) }\end{array}$ \\
\hline $\begin{array}{l}\text { Epidemiological/clinical data } \\
\text { indicating other atypicals }\end{array}$ & $\begin{array}{l}\text { Mycoplasma pneumoniae and } \\
\text { Chlamydia pneumoniae }\end{array}$ & Macrolide or doxycycline \\
\hline \multicolumn{3}{|l|}{$\begin{array}{l}\text { Gram-negative cover not } \\
\text { routinely necessary } \\
\text { (irrespective of patient's } \\
\text { age, or whether nursing } \\
\text { home resident) [97] }\end{array}$} \\
\hline \multicolumn{3}{|l|}{ Severe CAP } \\
\hline All cases & $\begin{array}{l}\text { Streptococcus pneumoniae, } \\
\text { Haemophilus influenzae, } \\
\text { Moraxella catarrhalis, } \\
\text { Staphylococcus aureus, } \\
\text { "atypical" agents and } \\
\text { Gram-negative enteric bacilli }\end{array}$ & $\begin{array}{l}\text { Cefotaxime/ceftriaxone }+ \text { macrolide } \pm \text { rifampin, } \\
\text { or benzylpenicillin }+ \text { respiratory FQ }\end{array}$ \\
\hline $\begin{array}{l}\text { Pseudomonas aeruginosa need } \\
\text { not be routinely covered }\end{array}$ & & \\
\hline
\end{tabular}

FQ: fluoroquinolone. 
cephalosporin (i.v.). In patients for whom legionella is unlikely, therapy failure will be seen in a few patients with mycoplasma or chlamydia pneumonia, which in turn may lead to a slightly prolonged length of stay. However, this must be balanced against the huge costs caused by problems with antibiotic resistance associated with overuse of antibiotics.

Intravenous versus oral treatment. Oral antibiotic treatment is probably safe and cost-effective in a large proportion of nonsevere CAP cases, if the patient is likely to take and absorb the drug given. In a randomised trial of patients with LRTI, of whom $\sim 40 \%$ had radiographically verified CAP, comparing oral amoxicillin+clavulanic acid with i.v. amoxicillin+ clavulanic acid or $i$.v. cephalosporins, there was no difference in outcome between the groups [41]. However, those who started on oral amoxicillin had significantly shorter hospital stays. An early switch (after 2-3 days) from i.v. to oral antibiotics in patients who have responded to therapy has also been shown to reduce duration of hospital stay without risk for the patient [98-100]. The safety of an early switch from i.v. to oral antibiotics is in accord with experience in Sweden, where i.v. treatment for the whole duration of the hospital stay has never been a common practice. In the surveys of management of CAP in Swedish departments of infectious diseases cited above, the median duration of $i$.v. treatment was 2 days (mean 3.1 days) in 1997 (unpublished data).

Optimal dosage and duration of treatment. An extensive review of the optimal dosage and duration of treatment is beyond the scope of the present article. In general, however, it is important for efficacy, as well as to avoid development of resistance, that high enough or frequent enough dosing is used rather than extending therapy for $>7-10$ days (except for treatment of legionellosis, where 2-3 weeks' duration is recommended). The time above the minimum inhibitory concentration of antibiotic is very important for the killing activity of most lower respiratory tract infection antibiotics, e.g. penicillins, other $\beta$-lactams and most macrolides. Thus, it is important to use short enough dose intervals for these agents. Conversely, quinolones show concentration-dependent bacterial killing, illustrated, for example, by the area under the curve in relation to the minimum inhibitory concentration of antibiotic inhibiting $90 \%$ of bacterial strains, which makes it more important that each dose is high enough.

\section{References}

1. Halls GA. The management of infections and antibiotic therapy: a European survey. $J$ Antimicrob Chemother 1993; 31: 985-1000.

2. Ortqvist A. Antibiotic treatment of communityacquired pneumonia in clinical practice: a European perspective. J Antimicrob Chemother 1995; 35: 205 212.

3. Huchon GJ, Gialdroni-Grassi G, Leophonte P, Manresa F, Schaberg T, Woodhead M. Initial antibiotic therapy for lower respiratory tract infection in the community: a European survey. Eur Respir $J$ 1996; 9: 1590-1595.

4. Rifenburg RP, Paladino JA, Hanson SC, Tuttle JA, Schentag JJ. Benchmark analysis of strategies hospitals use to control antimicrobial expenditures. Am J Health Syst Pharm 1996; 53: 2054-2062.

5. Cars O, Molstad S, Melander A. Variation in antibiotic use in the European Union. Lancet 2001; 357: 1851-1853.

6. Mandell LA, Niederman $M$ and the Canadian Community-Acquired Pneumonia Consensus Conference Group. Antimicrobial treatment of communityacquired pneumonia in adults: a conference report. Can J Infect Dis 1993; 4: 25-28.

7. Niederman MS, Bass JB Jr, Campbell GD, et al. Guidelines for the initial management of adults with community-acquired pneumonia: diagnosis, assessment of severity, and initial antimicrobial therapy. Am Rev Respir Dis 1993; 148: 1418-1426.

8. British Thoracic Society. Guidelines for the management of community-acquired pneumonia in adults admitted to hospital. Br J Hosp Med 1993; 49: 346350.

9. Huchon G, Woodhead M. Management of adult community-acquired lower respiratory tract infections. Eur Respir Rev 1998; 8: 61: 391-426.

10. Huchon G, Woodhead M and the ERS Task Force. Guidelines for management of adult communityacquired lower respiratory tract infections. Eur Respir J 1998; 11: 986-991.

11. Bartlett JG, Breiman RF, Mandell LA, File TM Jr. Community-acquired pneumonia in adults: guidelines for management. Clin Infect Dis 1998; 26: 811-838.

12. Bartlett JG, Dowell SF, Mandell LA, File TM Jr, Musher DM, Fine MJ. Practice guidelines for the management of community-acquired pneumonia in adults. Clin Infect Dis 2000; 31: 347-382.

13. Mandell LA, Marrie TJ, Grossman RF, Chow AW, Hyland RH, the Canadian Community-Acquired Pneumonia Working Group. Canadian guidelines for the initial management of community-acquired pneumonia: an evidence-based update by the Canadian Infectious Diseases Society and the Canadian Thoracic Society. Clin Infect Dis 2000; 31: 383-421.

14. Heffelfinger JD, Dowell SF, Jorgensen JH, et al. Management of community-acquired pneumonia in the era of pneumococcal resistance: a report from the Drug-Resistant Streptococcus pneumoniae Therapeutic Working Group. Arch Intern Med 2000; 160: 1399_ 1408.

15. Niederman MS, Mandell LA, Anzueto A, et al. Guidelines for the management of adults with communityacquired pneumonia. Diagnosis, assessment of severity, antimicrobial therapy, and prevention. Am J Respir Crit Care Med 2001; 163: 1730-1754

16. Ward DJ, Ayres JG. Pneumonia and acute bronchitis. Eur Respir Mon 2000; 5: 15, 105-127.

17. Macfarlane J. Lower respiratory tract infection and pneumonia in the community. Semin Respir Infect 1999; 14: 151-162.

18. Jokinen C, Heiskanen L, Juvonen $\mathrm{H}$, et al. Incidence of community-acquired pneumonia in the population of four municipalities in Eastern Finland. $A m J$ Epidemiol 1993; 137: 977-988.

19. Fine MJ, Smith MA, Carson CA, et al. Prognosis and outcomes of patients with community-acquired pneumonia. A meta-analysis. JAMA 1996; 275: 134-141. 
20. Marik PE. The clinical features of severe communityacquired pneumonia presenting as septic shock. $J$ Crit Care 2000; 15: 85-90.

21. Meehan TP, Fine MJ, Krumholz HM, et al. Quality of care, process, and outcomes in elderly patients with pneumonia. JAMA 1997; 278: 2080-2084.

22. Woodhead M, Gialdroni Grassi G, Huchon GJ, Leophonte P, Manresa F, Schaberg T. Use of investigations in lower respiratory tract infection in the community: a European survey. Eur Respir J 1996; 9: 1596-1600.

23. Gonzales R, Steiner JF, Sande MA. Antibiotic prescribing for adults with colds, upper respiratory tract infections, and bronchitis by ambulatory care physicians. JAMA 1997; 278: 901-904.

24. Granizo JJ, Aguilar L, Casal J, Garcia-Rey C, Dal-Re $\mathrm{R}$, Baquero F. Streptococcus pneumoniae resistance to erythromycin and penicillin in relation to macrolide and beta-lactam consumption in Spain (1979-1997). $J$ Antimicrob Chemother 2000; 46: 767-773.

25. Jokinen C. Incidence and microbial aetiology of pneumonia in the population of four municipalities in Eastern Finland. PhD Thesis. University of Kuopio, 1991; pp. 141.

26. Melbye H, Straume B, Brox J. Laboratory tests for pneumonia in general practice: the diagnostic values depend on the duration of illness. Scand J Prim Health Care 1992; 10: 234-240.

27. Melbye H, Berdal BP. Akutt bronkitt hos voksne. Kliniske funn, mikroorganismer og bruk av antibiotika. Tidsskr Nor Laegeforen 1994; 114: 814-817.

28. Smith RP, Lipworth BJ. C-reactive protein in simple community-acquired pneumonia. Chest 1995; 107: 1028-1031.

29. Ortqvist A, Hedlund J, Wretlind B, Carlstrom A, Kalin M. Diagnostic and prognostic value of interleukin-6 and C-reactive protein in communityacquired pneumonia. Scand J Infect Dis 1995; 27: 457 462.

30. Marrie TJ. Etiology of community-acquired pneumonia. In: Marrie TJ, ed. Community-acquired pneumonia. New York, NY, Kluwer Academic/Plenum publishers, 2001; pp. 131-141.

31. Jokinen C, Heiskanen L, Juvonen H, et al. Microbial etiology of community-acquired pneumonia in the adult population of 4 municipalities in Eastern Finland. Clin Infect Dis 2001; 32: 1141-1154.

32. Ortqvist A. Initial investigation and treatment of the patient with severe community-acquired pneumonia. Semin Respir Infect 1994; 9: 166-179.

33. Ramirez JA, Summersgill JT. Community-acquired pneumonia due to Chlamydia pneumoniae. In: Marrie TJ, ed. Community-Acquired Pneumonia. New York, NY, Kluwer Academic/Plenum publishers, 2001; pp. 501-509.

34. Kauppinen MT, Herva E, Kujala P, Leinonen M, Saikku P, Syrjala H. The etiology of communityacquired pneumonia among hospitalized patients during a Chlamydia pneumoniae epidemic in Finland. J Infect Dis 1995; 172: 1330-1335.

35. Woodhead M. Treatment of community-acquired pneumonia. In: Marrie TJ, ed. Community-acquired pneumonia. New York, NY, Kluwer Academicl Plenum publishers, 2001; pp. 163-178.

36. Dorca J, Manresa F. Community-acquired pneumonia: initial management and empirical treatment. Eur Respir Mon 1997; 3: 36-55.
37. Ruiz-Gonzalez A, Falguera M, Vives M, Nogues A, Porcel JM, Rubio-Caballero M. Community-acquired pneumonia: development of a bedside predictive model and scoring system to identify the aetiology. Respir Med 2000; 94: 505-510.

38. Lim WS, Macfarlane JT, Boswell TC, et al. Study of community acquired pneumonia aetiology (SCAPA) in adults admitted to hospital: implications for management guidelines. Thorax 2001; 56: 296-301.

39. Stahl JE, Barza M, DesJardin J, Martin R, Eckman MH. Effect of macrolides as part of initial empiric therapy on length of stay in patients hospitalized with community-acquired pneumonia. Arch Intern Med 1999; 159: 2576-2580.

40. Roson B, Carratala J, Tubau F, et al. Usefulness of betalactam therapy for community-acquired pneumonia in the era of drug-resistant Streptococcus pneumoniae: a randomized study of amoxicillin-clavulanate and ceftriaxone. Microb Drug Resist 2001; 7: 85-96.

41. Chan R, Hemeryck L, O'Regan M, Clancy L, Feely J. Oral versus intravenous antibiotics for community acquired lower respiratory tract infection in a general hospital: open, randomised controlled trial. $B M J$ 1995; 310: 1360-1362.

42. Laurichesse H, Robin F, Gerbaud L, et al. Empirical therapy for nonhospitalized patients with communityacquired pneumonia. Eur Respir J 1998; 11: 73-78.

43. Ortqvist A. In-hospital management of adults who have community-acquired pneumonia. Semin Respir Infect 1999; 14: 135-150.

44. Mundy LM, Oldach D, Auwaerter PG, et al. Implications for macrolide treatment in community-acquired pneumonia. Chest 1998; 113: 1201-1206.

45. File TM Jr, Segreti J, Dunbar L, et al. A multicenter, randomized study comparing the efficacy and safety of intravenous and/or oral levofloxacin versus ceftriaxone and/or cefuroxime axetil in treatment of adults with community-acquired pneumonia. Antimicrob Agents Chemother 1997; 41: 1965-1972.

46. Tremolieres F, de Kock F, Pluck N, Daniel R. Trovafloxacin versus high-dose amoxicillin $(1 \mathrm{~g}$ three times daily) in the treatment of community-acquired bacterial pneumonia. Eur J Clin Microbiol Infect Dis 1998; 17: 447-453.

47. Kinasewitz G, Wood RG. Azithromycin versus cefaclor in the treatment of acute bacterial pneumonia. Eur J Clin Microbiol Infect Dis 1991; 10: 872-877.

48. Bohte R, van't Wout JW, Lobatto S, et al. Efficacy and safety of azithromycin versus benzylpenicillin or erythromycin in community-acquired pneumonia. Eur J Clin Microbiol Infect Dis 1995; 14: 182-187.

49. Lode H, Garau J, Grassi C, et al. Treatment of community-acquired pneumonia: a randomized comparison of sparfloxacin, amoxycillin-clavulanic acid and erythromycin. Eur Respir J 1995; 8: 1999-2007.

50. Genne D, Siegrist HH, Humair L, Janin-Jaquat B, de Torrente A. Clarithromycin versus amoxicillinclavulanic acid in the treatment of communityacquired pneumonia. Eur J Clin Microbiol Infect Dis 1997; 16: 783-788.

51. O'Doherty B, Dutchman DA, Pettit R, Maroli A. Randomized, double-blind, comparative study of grepafloxacin and amoxycillin in the treatment of patients with community-acquired pneumonia. $J$ Antimicrob Chemother 1997; 40: Suppl. A, 73-81.

52. Norrby SR, Petermann W, Willcox PA, Vetter N, Salewski E. A comparative study of levofloxacin and 
ceftriaxone in the treatment of hospitalized patients with pneumonia. Scand J Infect Dis 1998; 30: 397404.

53. Aubier M, Verster R, Regamey C, Geslin P, Vercken JB. Once-daily sparfloxacin versus high-dosage amoxicillin in the treatment of community-acquired, suspected pneumococcal pneumonia in adults. Clin Infect Dis 1998; 26: 1312-1320.

54. Petitpretz P, Arvis P, Marel M, Moita J, Urueta J. Oral moxifloxacin $v s$ high-dosage amoxicillin in the treatment of mild-to-moderate, community-acquired, suspected pneumococcal pneumonia in adults. Chest 2001; 119: 185-195.

55. Ortqvist A. Pneumococcal pneumonia. In: Marrie TJ, ed. Community-acquired pneumonia. New York, NY, Kluwer Academic/Plenum publishers, 2001; pp. 427454.

56. Mathai D, Lewis MT, Kugler KC, Pfaller MA, Jones RN. Antibacterial activity of 41 antimicrobials tested against over 2773 bacterial isolates from hospitalized patients with pneumonia: I - results from the SENTRY Antimicrobial Surveillance Program (North America, 1998). Diagn Microbiol Infect Dis 2001; 39: 105-116.

57. Bryan CS, Talwani R, Stinson MS. Penicillin dosing for pneumococcal pneumonia. Chest 1997; 112: 16571664.

58. Choi EH, Lee HJ. Clinical outcome of invasive infections by penicillin-resistant Streptococcus pneumoniae in Korean children. Clin Infect Dis 1998; 26: 1346-1354.

59. Ewig S, Ruiz M, Torres A, et al. Pneumonia acquired in the community through drug-resistant Streptococcus pneumoniae. Am J Respir Crit Care Med 1999; 159: 1835-1842.

60. Feikin DR, Schuchat A, Kolczak M, et al. Mortality from invasive pneumococcal pneumonia in the era of antibiotic resistance, 1995-1997. Am J Public Health 2000; 90: 223-229.

61. Gomez-Barreto D, Calderon-Jaimes E, Rodriguez RS, de los Monteros LE. Clinical outcome of invasive infections in children caused by highly penicillinresistant Streptococcus pneumoniae compared with infections caused by penicillin-susceptible strains. Arch Med Res 2000; 31: 592-598.

62. Baquero F. Evolving resistance patterns of Streptococcus pneumoniae: a link with long-acting macrolide consumption? J Chemother 1999; 11: Suppl. 1, 35-43.

63. Waterer GW, Wunderink RG, Jones CB. Fatal pneumococcal pneumonia attributed to macrolide resistance and azithromycin monotherapy. Chest 2000; 118: 1839-1840.

64. Chen DK, McGeer A, de Azavedo JC, Low DE. Decreased susceptibility of Streptococcus pneumoniae to fluoroquinolones in Canada. N Engl J Med 1999; 341: 233-239.

65. Linares J, de la Campa AG, Pallares R. Fluoroquinolone resistance in Streptococcus pneumoniae. $N$ Engl J Med 1999; 341: 1546-1547 (discussion 7-8).

66. Ho PL, Que TL, Tsang DN, Ng TK, Chow KH, Seto WH. Emergence of fluoroquinolone resistance among multiply resistant strains of Streptococcus pneumoniae in Hong Kong. Antimicrob Agents Chemother 1999; 43: $1310-1313$.

67. Gordon JJ, Kauffman CA. Superinfection with Streptococcus pneumoniae during therapy with ciprofloxacin. Am J Med 1990; 89: 383-384.
68. Saito H, Kajita M, Shimokata K. Overwhelming pneumococcal pneumonia in a patient receiving ofloxacin for antimicrobial prophylaxis. Jpn J Med 1990; 29: 89-90.

69. Empey PE, Jennings HR, Thornton AC, Rapp RP, Evans ME. Levofloxacin failure in a patient with pneumococcal pneumonia. Ann Pharmacother 2001; 35: 687-690.

70. File TM Jr, Schlemmer B, Garau J, Cupo M, Young C. Efficacy and safety of gemifloxacin in the treatment of community-acquired pneumonia: a randomized, double-blind comparison with trovafloxacin. J Antimicrob Chemother 2001; 48: 67-74.

71. Norrby R. Linezolid - a review of the first oxazolidinone. Expert Opin Pharmacother 2001; 2: 293-302.

72. Felmingham D. Microbiological profile of telithromycin, the first ketolide antimicrobial. Clin Microbiol Infect 2001; 7: Suppl. 3, 2-10.

73. Finch R. Community-acquired pneumonia: the evolving challenge. Clin Microbiol Infect 2001; 7: Suppl. 3, 30-38.

74. Lim WS, Lewis S, Macfarlane JT. Severity prediction rules in community acquired pneumonia: a validation study. Thorax 2000; 55: 219-223.

75. Lim WS, Macfarlane JT. Defining prognostic factors in the elderly with community acquired pneumonia: a case controlled study of patients aged $\geqslant 75$ yrs. Eur Respir J 2001; 17: 200-205.

76. Fine MJ, Auble TE, Yealy DM, et al. A prediction rule to identify low-risk patients with communityacquired pneumonia. N Engl J Med 1997; 336: 243250.

77. Marras TK, Gutierrez C, Chan CK. Applying a prediction rule to identify low-risk patients with community- acquired pneumonia. Chest 2000; 118: 1339-1343.

78. Roson B, Carratala J, Dorca J, Casanova A, Manresa F, Gudiol F. Etiology, reasons for hospitalization, risk classes, and outcomes of community-acquired pneumonia in patients hospitalized on the basis of conventional admission criteria. Clin Infect Dis 2001; 33: 158-165.

79. Kalin M, Ortqvist A, Almela M, et al. Prospective study of prognostic factors in community-acquired bacteremic pneumococcal disease in 5 countries. $J$ Infect Dis 2000; 182: 840-847.

80. MacKay DN. Treatment of acute bronchitis in adults without underlying lung disease. $J$ Gen Intern Med 1996; 11: 557-562.

81. Smucny J, Fahey T, Becker L, Glazier R. Antibiotics for acute bronchitis (Cochrane Review). In: The Cochrane Library. Issue 4. Oxford, Update Software, 2001.

82. McCrory DC, Brown C, Gelfand SE, Bach PB. Management of acute exacerbations of COPD: a summary and appraisal of published evidence. Chest 2001; 119: 1190-1209.

83. Snow V, Lascher S, Mottur-Pilson C. The evidence base for management of acute exacerbations of COPD: clinical practice guideline, part 1. Chest 2001; 119: 1185-1189.

84. Sethi S, Murphy TF. Bacterial infection in chronic obstructive pulmonary disease in 2000: a state-of-theart review. Clin Microbiol Rev 2001; 14: 336-363.

85. Vereen L, Smart LM, George RB. Antibody coating and quantitative cultures of bacteria in sputum and 
bronchial brush specimens from patients with stable chronic bronchitis. Chest 1986; 90: 534-536.

86. Fagon JY, Chastre J, Trouillet JL, et al. Characterization of distal bronchial microflora during acute exacerbation of chronic bronchitis. Use of the protected specimen brush technique in 54 mechanically ventilated patients. Am Rev Respir Dis 1990; 142: 1004-1008.

87. Monso E, Ruiz J, Rosell A, et al. Bacterial infection in chronic obstructive pulmonary disease. A study of stable and exacerbated outpatients using the protected specimen brush. Am J Respir Crit Care Med 1995; 152: 1316-1320.

88. Saint S, Bent S, Vittinghoff E, Grady D. Antibiotics in chronic obstructive pulmonary disease exacerbations. A meta-analysis. JAMA 1995; 273: 957-960.

89. Anthonisen NR, Manfreda J, Warren CP, Hershfield ES, Harding GK, Nelson NA. Antibiotic therapy in exacerbations of chronic obstructive pulmonary disease. Ann Intern Med 1987; 106: 196-204.

90. Arancibia F, Ewig S, Martinez JA, et al. Antimicrobial treatment failures in patients with community-acquired pneumonia: causes and prognostic implications. Am J Respir Crit Care Med 2000; 162: 154-160.

91. Ortqvist A, Kalin M, Julander I, Mufson MA. Deaths in bacteremic pneumococcal pneumonia. A comparison of two populations - Huntington, WVa, and Stockholm, Sweden. Chest 1993; 103: 710-716.

92. Gleason PP, Kapoor WN, Stone RA, et al. Medical outcomes and antimicrobial costs with the use of the American Thoracic Society guidelines for outpatients with community-acquired pneumonia. JAMA 1997; 278: 32-39.
93. Gleason PP, Meehan TP, Fine JM, Galusha DH, Fine MJ. Associations between initial antimicrobial therapy and medical outcomes for hospitalized elderly patients with pneumonia. Arch Intern Med 1999; 159: 2562-2572.

94. Houck PM, MacLehose RF, Niederman MS, Lowery JK. Empiric antibiotic therapy and mortality among Medicare pneumonia inpatients in 10 western states: 1993, 1995, and 1997. Chest 2001; 119: 1420-1426.

95. Marrie TJ, Lau CY, Wheeler SL, Wong CJ, Vandervoort MK, Feagan BG. A controlled trial of a critical pathway for treatment of community-acquired pneumonia. JAMA 2000; 283: 749-755.

96. Dean NC, Silver MP, Bateman KA, James B, Hadlock CJ, Hale D. Decreased mortality after implementation of a treatment guideline for communityacquired pneumonia. Am J Med 2001; 110: 451-457.

97. Lim WS, Macfarlane JT. A prospective comparison of nursing home acquired pneumonia with community acquired pneumonia. Eur Respir J 2001; 18: 362-368.

98. Ramirez JA, Srinath L, Ahkee S, Huang A, Raff MJ. Early switch from intravenous to oral cephalosporins in the treatment of hospitalized patients with community-acquired pneumonia. Arch Intern Med 1995; 155: 1273-1276.

99. Siegel RE, Halpern NA, Almenoff PL, Lee A, Cashin $\mathrm{R}$, Greene JG. A prospective randomized study of inpatient i.v. antibiotics for community-acquired pneumonia. The optimal duration of therapy. Chest 1996; 110: 965-971.

100. Ramirez JA, Bordon J. Early switch from intravenous to oral antibiotics in hospitalized patients with bacteremic community-acquired Streptococcus pneumoniae pneumonia. Arch Intern Med 2001; 161: 848-850. 